\title{
Current Controversies in Reconstructive Surgery of the Anterior Urethra: a Clinical Overview
}

\author{
Guido Barbagli, Salvatore Sansalone, Rados Djinovic, Giuseppe Romano, Massimo Lazzeri
}

Center for Reconstructive Urethral Surgery (GB, SS, GR, ML), Arezzo, Italy and Sava Perovic Foundation (RD), Belgrade, Serbia

\section{ABSTRACT}

We performed an overview of the surgical techniques suggested for the treatment of anterior urethral strictures using MEDLINE. In applying the MEDLINE search, we used the "MeSH" (Medical Subject Heading) and "free text" protocols. The MeSH search was conducted by combining the following terms: "urethral stricture", "flap", "graft", "oral mucosa", "urethroplasty", "urethrotomy" and "failed hypospadias". Multiple "free text" searches were performed individually applying the following terms through all fields of the records: "reconstructive urethral surgery", "end-to-end anastomosis", "one-stage", "two stage". Descriptive statistics of the articles were provided. Meta-analyses were not employed. Seventy-eight articles were determined to be germane in this review. Six main topics were identified as controversial in anterior urethra surgery: the use of oral mucosa vs penile skin; the use of free grafts vs pedicled flaps in penile urethroplasty; the use of grafts vs anastomotic repair in bulbar urethral strictures; the use of dorsal vs ventral placement of the graft in bulbar urethroplasty; the use of definitive perineal urethrostomy vs one-stage repair in complex urethral strictures; the surgical options for patients with failed hypospadias repair. Different points of view are documented and presented in the literature by various authors from different countries. The aim of this clinical overview is to survey the main controversial issues in surgical reconstruction of the anterior urethra focusing on the use of flap or graft, substitute material, type of surgery and challenging situations, such as failed hypospadias or complex urethral stricture repair.

\section{ARTICLE INFO}

\section{Key words:}

Urethra; urethral stricture; urethroplasty; oral mucosa; genital skin

Int Braz J Urol. 2012; 38: 307-16

Submitted for publication: October 19, 2011

Accepted after revision:

February 12, 2012

\section{INTRODUCTION}

Various surgical techniques are currently being used to repair anterior urethral strictures with the goal of reducing morbidity and obtaining the best outcome with few complications; however, the superiority of one surgical technique over another has not yet been clearly defined (1-3). The urologist is thus requested to be familiar with the use of various surgical tech- niques to deal with any condition of the urethra that might emerge at the time of surgery. Urethral reconstruction is a continuing challenge and excellent results can be obtained with today's techniques, with single-stage repairs on the increase and continued improvements in patient outcome, but a significant advantage is to be gained by having tissue engineered material available for urethral reconstruction in the not so distant future $(4,5)$. In developed countries, 
strictures of the anterior urethra are commonly caused by external trauma, catheterization and transurethral surgery, whereas lichen sclerosus is reported to be the most frequent cause of distal penile urethral strictures $(6,7)$. In less developed countries, pelvic trauma or explosive blast and gunshot injury are the most prevalent causes of urethral injury and disease mainly involving the posterior tract (8). Treatment options for urethral strictures include dilation, urethrotomy and reconstructive surgical techniques, and no one technique is appropriate for all stricture diseases (9). Dilation and urethrotomy continue to be the most commonly used approach despite many patients progressing to eventually requiring surgical repair (9). Some authors suggest that endoscopic treatment of urethral strictures using dilation or urethrotomy exacerbates scar formation, thus adding to stricture length and severity, complicating subsequent open repair (10). Open urethroplasty is regarded as the gold standard treatment of urethral strictures and this surgical therapy should not be withheld solely on the basis of age, as older men tolerate urethroplasty well and without complications $(11,12)$. Minimizing time in surgery, maximizing adjuvant pain therapy and decreasing the incidence and severity of side effects have permitted most patients to leave the hospital within four hours of surgery (13). Finally, some authors suggest that urethrotomy and dilation work less than we believe and patients with urethral stricture disease should be referred to a center of expertise for the best available treatment options $(14,15)$.

The aim of this overview is to survey the main issues in surgical reconstruction of the anterior urethra, focusing on the use of flap or graft, substitute material, type of surgery and challenging situations, such as failed hypospadias and panurethral stricture.

\section{MATERIALS AND METHODS}

Although the aim of the paper was not to conduct a systematic review or meta-analysis (the reason for which the manuscript does not comply with The PRISMA Statement), an overview of the literature was performed using MED-
LINE. In applying the MEDLINE search we used "MeSH" (Medical Subject Heading) and "free text" protocols. Specifically, the MeSH search was conducted by combining the following terms retrieved from the MeSH browser provided by MEDLINE: "urethral stricture", "flap", "graft", "oral mucosa", "urethroplasty", "urethrotomy" and "failed hypospadias". Multiple "free text" searches were performed by applying the following terms individually through all fields of the records: "reconstructive urethral surgery", "end-to-end anastomosis", "one-stage", "two stage". The search was restricted to the English language.

The results of our research were divided according to different topics regarding reconstructive urethral surgery which are currently under discussion, as points of view on these topics vary in the literature and at urological meetings.

Six main topics were identified as current controversies in anterior urethra surgery: the use of oral mucosa vs. penile skin; the use of free grafts vs. pedicled flaps in penile urethroplasty; the use of grafts vs. anastomotic repair in bulbar urethral strictures; the use of dorsal vs. ventral placement of the graft in bulbar urethroplasty; the use of definitive perineal urethrostomy vs. one-stage repair in complex urethral strictures; the surgical options for patients with failed hypospadias repair.

\section{Substitute material: oral mucosa vs skin}

In 1953, Presman and Greenfield first reported the reconstruction of the bulbar urethra with satisfactory result using a free fullthickness skin graft from the prepuce (16). In 1956, Peyton and Headstream, following Presman and Greenfield's suggestions, reported the construction of the bulbar urethra using a split thickness skin graft from the prepuce (17). In 1961, Devine and Horton fully described the use of preputial skin to repair hypospadias using a one-stage technique (18). In 1963, Devine et al., after successfully using preputial skin in onestage hypospadias repair, popularized the use of the free skin graft in the repair of urethral strictures (19). From 1973 to 1985, beginning 
with these preliminary studies, several authors reported the use of preputial skin grafts in urethral reconstruction, suggesting a range of different surgical techniques (20-31).

In 1993, El-Kasaby et al. first suggested the use of oral mucosal graft from the lip in the management of penile and bulbar urethral strictures (32). From 1966 to 2006, a total of 1,267 studies were reported in the literature on the use of oral mucosa in reconstructive surgery. These included 1,353 cases involving oral mucosabased urethroplasty for the repair of defects associated with urethral strictures and hypospadias / epispadias (33). In these reports, 724 (53.5\%) urethroplasties were performed for urethral strictures, while $629(46.5 \%)$ were performed for hypospadias / epispadias repair (33). Reconstruction for urethral stricture and hypospadias / epispadias was successful in 418 (66.5\%) and 553 (76.4\%) cases, respectively (33).

Is oral mucosa really superior to skin as a substitute material in urethroplasty?

In 2005, Alsikafi et al. compared the outcome of 95 oral graft and 24 penile skin graft urethroplasty in an effort to answer whether oral mucosa is really superior to the skin (34). The overall success rate of skin urethroplasty was $84 \%$ with a mean follow-up of 201 months, while the success rate of oral urethroplasty was $87 \%$ with a mean follow-up of 48 months (34). These authors concluded that penile skin and oral mucosa are both excellent materials for substitution urethroplasty, with a comparable success rate, though penile skin appears to have a longer follow-up (34). Nevertheless, these authors do not report, in the Abstract of their paper, which type of urethroplasty is better (penile vs. bulbar, one-stage vs. two-stage), but instead compare the skin graft to the oral mucosa graft, creating a great limitation of these studies (34). In 2008, Barbagli et al. reviewed a large series, 375 patients, who underwent one-stage bulbar urethroplasty using either penile skin or oral mucosal grafts. The authors concluded that oral mucosa is superior to skin for one-stage bulbar urethroplasty, showing an overall success rate of $82.8 \%$ compared to $59.6 \%$ (35).
Markiewicz et al. documented the main biological and clinical characteristics of oral mucosa that justify why oral mucosa has received increased attention and popularity in the field of urological surgery $(33,36)$. Oral mucosa is hairless, is readily available in all patients and is easily harvested from the cheek with low postoperative oral morbidity and high patient satisfaction (37). In patients requiring a long graft, oral mucosa is easily harvested from both cheeks (37). Oral mucosa is easy to handle because it has a thick elastin-rich epithelium, promoting its use as a graft employing original inlay or onlay techniques in one- or two-stage steps $(33,36)$. Oral mucosa has a thin and highly vascular lamina propria that facilitates inosculation and imbibition $(33,36)$. Oral mucosa avoids cosmetic consequences caused by the use of genital or extragenital skin because it leaves a concealed donor site scar $(33,36)$. Oral mucosa is resistant to infection. Because it hosts a number of microorganisms, the tissue's inflammatory response to the organism is minimal $(33,36)$. There are multiple immunological processes intrinsic to the oral mucosa that makes it impervious to native flora colonization $(33,36)$. Histological studies have demonstrated that oral mucosa is highly compatible with the urethral recipient site, at times being indistinguishable from surrounding tissues $(33,36)$. The structural integrity of oral mucosa remains intact following transplantation to a distant site $(33,36)$. Oral mucosa is elastic and resilient, and when exposed to compression, stretching and shearing forces, it is highly resilient, due to its particular lamina propria-oral epithelium interface $(33,36)$. Oral mucosa is easy to adapt to any type of urethroplasty and it is rarely affected by lichen sclerosus disease $(33,36)$.

\section{Penile urethroplasty: graft vs. flap}

Penile urethroplasty can be a simple procedure in patients with a normal penis, but it can be a difficult challenge in men with strictures associated with failed hypospadias repair or genital lichen sclerosus in which the penis is fully involved by the disease. Basically, the choice of a surgical procedure for repair of penile urethral strictures is based on the etiology 
of the disease (38). When the penile skin, urethral plate, corpus spongiosum and dartos fascia are available for urethral reconstruction, one-stage repair is the surgery of choice worldwide. In patients who have experienced failed hypospadias repair, where the penile skin, urethral plate and dartos fascia are not fully usable for urethral reconstruction, staged urethroplasty is suggested (38). In patients with lichen sclerosus, the use of oral mucosa is mandatory since lichen sclerosus is a skin disease and any skin that would be used for the repair is already or may become diseased (39-41). The surgical technique for penile urethral reconstruction must also be based on the proper anatomic characteristics of the penile tissues to ensure flap or graft take and survival. The use of flaps or grafts should not compromise penile length or cause penile chordee, and certainly should not untowardly affect penile appearance.

In 1968, Orandi first reported the reconstruction of the anterior urethra using a pedicled skin flap (42). In 1993, McAninch first described the reconstruction of extensive urethral strictures using a circular fasciocutaneous penile flap (43). The surgical technique described by McAninch still represents the most important and advanced evolution of Orandi's flap. The use of circular fasciocutaneous penile flap for anterior urethroplasty, and specifically penile urethroplasty, renders a durable 5- and 10-year estimated stricture-free survival rate of $84 \%$ and $79 \%$, respectively, in properly selected patients (44).

Penile urethroplasty using a graft was greatly improved in 1999 when Hayes and Malone suggested an evolution of Snodgrass's longitudinal incision of the urethral plate, laying an oral mucosal graft into the incised urethral plate (45). A striking evolution of Hayes and Malone's technique appeared in 2001, when Asopa et al. popularized a similar technique for penile stricture repair (46). Asopa's technique represents the beginning of a new era in reconstructive urethral surgery with the use of free graft techniques, mainly in the repair of penile urethral strictures (44). In our experience, Asopa's penile urethroplasty presents numerous advantages compared to the use of extensive pe- nile skin flap; it maintains great respect for the penile shaft components (44).

This technique does not require extensive training in reconstructive tissue transfer procedures and may be done using either oral mucosa or preputial skin graft with a minimally invasive approach (circumcision or simple perineal incision) (44). This technique should also be used in selected patients with failed hypospadias repair or lichen sclerosus, but is not suggested in patients with a narrow and fibrous urethral plate (44). In our experience using Asopa's technique, oral mucosa was better than skin graft material, but the difference (82\% vs. 78\%) does not justify the use of oral mucosa as a first choice (47). The choice of substitute material (oral mucosa vs. preputial skin) should be based primarily on surgeon preference and background.

The controversy over the best means of reconstructing the penile urethra, using flap or graft, is still under debate (44). The current literature, however, does not clearly support the use of one technique over the other, and some prospective randomized studies on the use of graft versus flap are not useful because they compare a non-homogeneous series of patients and stricture disease (48). At present, we are uncertain about the proper anatomic characteristics that the penis should have to ensure that the free graft takes, as penile spongiosum tissue and dartos fascia do not ensure sufficient support for the graft in all patients. In which patients will the use of a vascularized pedicled flap have a better chance of success than a free graft? In the future, more homogeneous and larger series of patients with adequate follow-up might clarify whether the use of a free graft is preferable to the use of a vascularized flap.

Bulbar urethroplasty: graft vs end-to-end anastomotic repair

The current literature suggests that the surgical technique for the repair of the bulbar urethral stricture should be selected according to stricture length $(9,38)$. Primary end-to-end anastomosis is suggested for $1-2 \mathrm{~cm}$ strictures, augmented roof-strip anastomosis is suggested for 3-5 cm strictures, and substitution urethro- 
plasty is suggested for longer strictures $(9,38)$. In patients with strictures associated with local adverse conditions, staged urethroplasty is preferred $(9,38)$. Since the 2009 American Urological Association (AUA) Meeting, the controversy over the use of end-to-end anastomosis or augmented roof strip anastomosis in non-traumatic bulbar urethral strictures has been open to debate (49). Transecting the urethra to perform an end-to-end anastomosis or augmented roof strip anastomosis allows complete removal of the scarred tissue, but may cause vascular and neuronal damage to the urethra and penis, thus promoting post-operative sexual dysfunction (49). Not transecting the urethra is a vascular and neuronal sparing procedure, but it does not allow removal of the scarred tissue (49). In strictures following blunt perineal trauma and bulbar urethral injury, removal of the traumatic scarred tissues and performance of a direct anastomosis between the two healthy urethral edges is mandatory, as not removing this tissue is the cause of stricture recurrence over time. In non-traumatic urethral strictures, is it mandatory to transect the urethra and remove the tissues or is it sufficient to open the urethra and perform only an augmentation of the original urethral plate?

Traumatic (following blunt perineal trauma and urethral injury) short bulbar strictures are generally amenable to scar excision and direct anastomosis using a simple perineal approach. This technique has a 90-95\% success rate, as reported by some authors $(50,51)$. Guralnick and Webster suggested that end-to-end anastomosis is appropriate only for bulbar strictures of $1 \mathrm{~cm}$ or less because excision of a $1 \mathrm{~cm}$ urethral segment with opposing $1 \mathrm{~cm}$ proximal and distal spatulations results in a $2 \mathrm{~cm}$ urethral shortening, which may be adequately accommodated by the elasticity of the mobilized bulbar urethra without chordee (52). These authors emphasize that longer excision risks penile shortening or chordee, even using lengthening maneuvers (52). On the contrary, Morey and Kizer also suggested the use of an extended anastomotic approach in patients with proximal bulbar urethral strictures longer than $2.5 \mathrm{~cm}$ (53). Al-Qudah and Santucci reported post-operative sexual dysfunctions (chordee and erectile dysfunction) in 18\% of patients who underwent anastomotic urethroplasty, and concluded that oral mucosal urethroplasty had a superior success rate and fewer complications than anastomotic urethroplasty, even for short strictures (54). Barbagli et al. investigated, using a non-validated questionnaire, 60 patients who underwent bulbar end-to-end anastomosis, and reported that $23.3 \%$ of patients experienced ejaculatory dysfunction, $18.3 \%$ had decreased glans sensitivity, $11.6 \%$ had a glans that was neither full nor swollen during erection, and 1.6\% had a cold glans during erection (51). No patient complained of penile chordee or impotence (51). Petersen and Webster suggested that for bulbar urethral strictures ranging from 2 to $4 \mathrm{~cm}$, the best option is augmented anastomotic urethroplasty (9). During this procedure, the worst section of the stricture is removed and the urethra is reanastomosed and dorsally augmented with a free graft (9).

Other authors also suggest the use of this procedure in patients undergoing urethroplasty for strictures that contain a particularly narrow or dense area of 1-2 cm (55). However, none of these authors, who also suggest transection of the urethra in non-traumatic bulbar urethral strictures, report any investigation on the incidence of post-operative sexual complications in these patients, a factor that greatly limits these studies $(9,52-55)$. In the future, large and homogeneous series of patients with adequate follow-up are necessary to investigate the incidence of post-operative sexual dysfunction in patients who have undergone full transection of the bulbar urethra for anastomotic repair in non-traumatic strictures.

\section{Bulbar urethroplasty: dorsal vs ventral graft} One-stage oral mucosal graft urethroplasty represents the most widespread method for the repair of bulbar urethral strictures due to its highly vascular spongiosum tissue. The location of the free graft on the dorsal or ventral urethral surface has become a contentious issue since Barbagli et al. described, in 1996, the technique of dorsal onlay graft urethroplasty (56-58). Wessells suggests a list of the techni- 
cal advantages of bulbar ventral onlay urethroplasty (59). Armenakas emphasizes that ventral graft placement, requiring less urethral dissection and mobilization, is technically easier (60). Success with bulbar oral mucosal grafts has been high with a dorsal $(57,58,61-63)$ or ventral $(59,60,64,65)$ graft location, and the different graft positions have shown no difference in success rate $(35,66,67)$. Barbagli et al. showed that placement of the grafts on the ventral, dorsal or lateral surface of the bulbar urethra provided the same success rates (83\% to $85 \%$ ) and stricture recurrence was uniformly distributed in all patients (66). In our daily clinical practice, we currently use the ventral graft location in all patients with non-traumatic urethral strictures located in the proximal bulbar urethra (68). In patients with non-traumatic urethral strictures located in the distal bulbar urethra, we prefer the dorsal graft location (69).

\section{Complex urethral strictures: definitive perineal urethrostomy vs one-stage repair}

Complex anterior urethral strictures include strictures simultaneously involving the penile and bulbar urethra (panurethral stricture) and strictures in patients who had undergone numerous prior failed urethroplasties. Lichen sclerosus is the most frequent cause of pan-urethral strictures (70) and failed hypospadias repair is the most frequent cause of complex anterior urethral strictures $(71,72)$. How to treat patients with complex urethral stricture disease is still a difficult and controversial issue in the field of reconstructive urethral surgery. In these patients, the use of one-stage techniques requires careful preoperative patient evaluation and selection and represents a complex and challenging surgery (73). Breyer et al. reported that stricture length (greater than $4 \mathrm{~cm}$ ) or previous failed urethroplasty are predictive of failure after urethroplasty (74). Some authors suggest that heroic measures or one-stage repair may not always be justified in extensive urethral strictures associated with a high risk of failure $(75,76)$. Strictures associated with local adverse conditions, such as fistula, false passage, abscess, cancer or repeated failed urethroplasty are best treated with staged procedures $(75,76)$. Perineal urethrostomy can be a temporary or definitive solution to the complex urethral stricture. As some patients choose not to have the urethra reconstructed in a second or third step and continue to void through a perineal urethrostomy, the first stage becomes a definitive procedure $(75,76)$. Some patients (mean age 53 years) having undergone failed hypospadias repair (mean previous operations 4.2) or repeated failed urethroplasty (mean previous operations 4.1) or other conditions requiring periodic dilation or urethrotomy to avoid urinary retention informed us "I underwent innumerable prior failed operations. I am tired." (76). These patients could not accept the possibility of another complete urethroplasty failure (76). In other patients with aggressive stricture recurrence following repeated urethroplasties, some urologists have said "I don't know which kind of urethroplasty is best to perform because I do not know the pathological status of your urethra" (76). In these patients, it is the status of the urethral tissues that conditions the surgical approach and not the technical expertise of the surgeon (76). Likely, the experienced urethral surgeon is able to perform one-stage repair in a majority of urethral strictures, but is it the correct approach? Is it always correct to transplant an oral graft in ischemic or scarred urethral tissue? Is it correct to once again transect the urethra in patients who have already undergone a prior end-to-end or augmented roof strip anastomosis, showing urethral shortening? Is it correct to do one-stage urethroplasty in patients with multiple failed treatments of urethral strictures that began 20-30 years ago and showing multiple bladder diverticula or detrusor acontractility? (76).

An important question regards the patient's satisfaction and acceptance of the urinary diversion through a perineal urethrostomy. Onestage repair provides restoration of micturition through normal standing position and avoids patient discomfort caused by perineal urinary diversion that may not be accepted by the patient for religious, hygienic, cultural or psychological reasons; although, in our experience, many patients in this population are already accustomed to seated voiding because of age and prior void- 
ing difficulties. In contrast to complex one-stage reconstruction, perineal urethrostomy is a minor surgical intervention that can be performed on an outpatient basis, providing an early return to normal activities. $(75,76)$ In older patients or patients with multiple failed repairs, serious comorbidity, histologically severe disease or a severely scarred urethral plate, we discussed the possibility of performing a temporary or definitive perineal urethrostomy with the patient. However, the final choice was selected on the basis of patient decision alone $(75,76)$.

\section{Surgical options in patients with failed hypo- spadias repair}

How to treat patients with failed hypospadias repair represents a difficult issue in the field of reconstructive urethral surgery, and the current literature does not provide any sure guideline.

Recently, two studies on the largest series of patients (1,176 cases) with failed hypospadias repair to date were published in the literature, and the suggestions coming from these two studies were interesting enough to be here presented and discussed $(77,78)$. The authors reported that, from 1988 to 2007, 1,176 patients with a mean age of 31 years (range 1 to 76 years) were treated for complications after initial hypospadias repair, consisting of 953 patients in Serbia and 223 in Italy (78). Patients were stratified into four different groups according to the involvement of a single or multiple anatomical compartment(s) of the male genitalia at the time of surgery. Group 1 included patients who underwent only urethral surgery; group 2 included patients who underwent only corpora cavernosa surgery; group 3 included patients who underwent urethral and corpora cavernosa surgery; group 4 included patients who underwent complex reconstructive surgery including urethral, corpora cavernosa, glans and penile skin resurfacing (78). It is interesting to note that only 301 patients (25.5\%) required only urethral surgery for meatal, penile or bulbar stricture, retrusive meatus, fistula or diverticulum (78). Out of the 1,176 cases, 60 (5.2\%) required only corpora cavernosa surgery for residual penile curvature, corpora cavernosa defor- mity, penile shortening or torsion, and 8 (13.4\%) patients in this group required corpora cavernosa resurfacing using grafting material as indicated in surgery for Peyronie's disease (78). In 166 cases (14.1\%), surgery involved both the urethra and corpora cavernosa functions for stricture, fistula or diverticulum associated with some degree of residual glans/penile curvature (78). But it is very interesting to note that in this study, 55.2\% of patients (649 cases) required complex reconstructive surgery for complications fully involving the genitalia with glans dehiscence, partial glans necrosis, glans torsion or curvature, loss of penile or scrotal skin, midline septum, penile skin torsion, abnormal peno-scrotal or peno-pubic junction, buried penis, trapped penis, other problems (78). The final message from this study is that failed hypospadias repair is not a problem for the pediatric urologists to solve as the mean age of the patients was 31 years, or for the urethral surgeon, as the surgery was restricted to the urethra in only $25.5 \%$ of the cases (78). To greatly improve anatomical and functional outcome in patients with failed hypospadias repair, it is essential to create centers specially dedicated to the treatment of these patients. Only full collaboration between the urethral surgeon and the surgeon widely skilled in reconstructive surgery of the corpora cavernosa (penile prosthesis implantation, surgery for Peyronie's disease, surgery for male to female transition) can ensure the best cosmetic and functional outcome (78). Shouldn't patients with complex failed hypospadias repair be referred to a centre of expertise? Medically and ethically speaking, it is the right thing to do (78).

\section{CONCLUSIONS}

Reconstructive surgery of the anterior urethra is a continually evolving process and new controversies must be discussed and resolved so that the patient receives the highest possible standard of care. This objective will become possible by increasing the use of minimally invasive techniques, developing new research and translating basic scientific results into daily clinical practice. 


\section{CONFLICT OF INTEREST}

\author{
None declared.
}

\section{REFERENCES}

1. Andrich DE, Mundy AR: What is the best technique for urethroplasty? Eur Urol. 2008; 54: 1031-41.

2. Mundy AR, Andrich DE: Urethral strictures. BJU Int. 2011; 107: 6-26.

3. Mangera A, Patterson JM, Chapple CR: A systematic review of graft augmentation urethroplasty techniques for the treatment of anterior urethral strictures. Eur Urol. 2011; 59: 797-814.

4. McAninch JW: Urethral reconstruction: a continuing challenge. J Urol. 2005; 173: 7.

5. Carson CC: Editorial. Urethroplasty: a model for international progress in urology. Contemp Urol. 2006; 18: 11.

6. Lumen N, Hoebeke P, Willemsen P, De Troyer B, Pieters R, Oosterlinck W: Etiology of urethral stricture disease in the 21st century. J Urol. 2009; 182: 983-7.

7. Fenton AS, Morey AF, Aviles R, Garcia CR: Anterior urethral strictures: etiology and characteristics. Urology. 2005; 65: 1055-8.

8. Pratap A, Agrawal CS, Tiwari A, Bhattarai BK, Pandit RK, Anchal N: Complex posterior urethral disruptions: management by combined abdominal transpubic perineal urethroplasty. J Urol. 2006; 175: 1751-4.

9. Peterson AC, Webster GD: Management of urethral stricture disease: developing options for surgical intervention. BJU Int. 2004; 94: 971-6.

10. Waxman SW, Morey AF: Management of urethral strictures. Lancet. 2006; 367: 1379-80.

11. Morey A: Urethral stricture is now an open surgical disease. J Urol. 2009; 181: 953-4

12. Santucci RA, McAninch JW, Mario LA, Rajpurkar A, Chopra AK, Miller KS, et al.: Urethroplasty in patients older than 65 years: indications, results, outcomes and suggested treatment modifications. J Urol. 2004; 172: 201-3.

13. MacDonald MF, Al-Qudah HS, Santucci RA: Minimal impact urethroplasty allows same-day surgery in most patients. Urology. 2005; 66: 850-3.

14. Rourke KF, Jordan GH: Primary urethral reconstruction: the cost minimized approach to the bulbous urethral stricture. J Urol. 2005; 173: 1206-10.

15. Santucci RA: Should we centralize referrals for repair of urethral stricture? J Urol. 2009; 182: 1259-60.

16. Presman D, Greenfield DL: Reconstruction of the perineal urethra with a free full-thickness skin graft from the prepuce. J Urol. 1953; 69: 677-80.
17. Peyton AB, Headstream JW: Construction of perineal urethra by split thickness skin graft. J Urol. 1956; 76: 90-3.

18. Devine CJ Jr, Horton CE: A one stage hypospadias repair. $J$ Urol. 1961; 85: 166-72.

19. Devine PC, Horton CE, Devine CJ Sr, Devine CJ Jr, Crawford $\mathrm{HH}$, Adamson JE: Use of full thickness skin grafts in repair of urethral strictures. J Urol. 1963; 90: 67-71.

20. Brannan W, Ochsner G, Fuselier HA Jr.: Anterior urethral strictures: experience with free graft urethroplasty. J Urol. 1973; 109: 265-7.

21. McKinney DE, Chenault OW Jr.: Experiences with Devine inlay graft urethroplasty. Urology. 1975; 5: 487-91.

22. Kibbey RG 3rd: Patch graft urethroplasty: a review with emphasis on use for strictures in the region of the membranous urethra. J Urol. 1976; 115: 155-8.

23. Brannan W, Ochsner MG, Fuselier HA, Goodlet JS: Free full thickness skin graft urethroplasty for urethral stricture: experience with 66 patients. J Urol. 1976; 115: 677-80.

24. Berger B, Sykes Z, Freedman M: Patch graft urethroplasty for urethral stricture disease. J Urol. 1976; 115: 681-4.

25. Krane RJ, Wysocki JP, Schwartz B: Dermal patch urethroplasty: experimental and clinical experience. J Urol. 1977; 118: $262-5$

26. Betts JM, Texter JH Jr, Crane DB: Single stage urethroplasty as treatment for stricture disease. J Urol. 1978; 120: 412-3.

27. De Sy W, Oosterlinck W: One-stage urethroplasty with free skin graft. Eur Urol. 1978; 4: 411-3.

28. Oswalt GC Jr, Lloyd LK, Bueschen AJ: Full thickness skin graft urethroplasty for anterior urethral strictures. Urology. 1979; 13: 45-8.

29. Hendren WH, Crooks KK: Tubed free skin graft for construction of male urethra. J Urol. 1980; 123: 858-61.

30. Blum JA, Feeney MJ, Howe GE, Steel JF: Skin patch urethroplasty: 5-year followup. J Urol. 1982; 127: 909.

31. Nielsen MA, Bueschen AJ, Lloyd LK: Free full thickness (patch) graft urethroplasty: Iong-term follow-up. Urology. 1985; 26: 562-5.

32. el-Kasaby AW, Fath-Alla M, Noweir AM, el-Halaby MR, Zakaria W, el-Beialy $\mathrm{MH}$ : The use of buccal mucosa patch graft in the management of anterior urethral strictures. J Urol. 1993; 149: 276-8.

33. Markiewicz MR, Lukose MA, Margarone JE 3rd, Barbagli G, Miller KS, Chuang SK: The oral mucosa graft: a systematic review. J Urol. 2007; 178: 387-94.

34. Alsikafi NF, Eisenberg M, McAninch JW: Long-term outcomes of penile skin graft versus buccal mucosal graft for substitution urethroplasty of the anterior urethra. J Urol. 2005; 173: 87.

35. Barbagli G, Guazzoni G, Lazzeri M: One-stage bulbar urethroplasty: retrospective analysis of the results in $375 \mathrm{pa}-$ tients. Eur Urol. 2008; 53: 828-33. 
36. Markiewicz MR, Margarone JE 3rd, Barbagli G, Scannapieco FA: Oral Mucosa Harvest: an Overview of Anatomic and Biologic Consideration. Eur Assoc Urol. 2007; 5: 179-87.

37. Barbagli G, Vallasciani S, Romano G, Fabbri F, Guazzoni G, Lazzeri M: Morbidity of oral mucosa graft harvesting from a single cheek. Eur Urol. 2010; 58: 33-41.

38. Barbagli G, Palminteri E, Lazzeri M, Guazzoni G: Anterior urethral strictures. BJU Int. 2003; 92: 497-505.

39. Venn SN, Mundy AR: Urethroplasty for balanitis xerotica obliterans. Br J Urol. 1998; 81: 735-7.

40. Greenwell TJ, Venn SN, Mundy AR: Changing practice in anterior urethroplasty. BJU Int. 1999; 83: 631-5.

41. Andrich DE, Mundy AR: Substitution urethroplasty with buccal mucosal-free grafts. J Urol. 2001; 165: 1131-3.

42. Orandi A: One-stage urethroplasty. Br J Urol. 1968; 40: 717-9.

43. McAninch JW: Reconstruction of extensive urethral strictures: circular fasciocutaneous penile flap. J Urol. 1993; 149: 488-91.

44. Barbagli G, Lazzeri M: Penile urethral stricture reconstruction--flap or graft? Graft. J Urol. 2011; 186: 375-6.

45. Hayes MC, Malone PS: The use of a dorsal buccal mucosal graft with urethral plate incision (Snodgrass) for hypospadias salvage. BJU Int. 1999; 83: 508-9.

46. Asopa HS, Garg M, Singhal GG, Singh L, Asopa J, Nischal A: Dorsal free graft urethroplasty for urethral stricture by ventral sagittal urethrotomy approach. Urology. 2001; 58: 657-9.

47. Barbagli G, Morgia G, Lazzeri M: Retrospective outcome analysis of one-stage penile urethroplasty using a flap or graft in a homogeneous series of patients. BJU Int. 2008; 102: 853-60. Erratum in: BJU Int. 2008; 102: 1772.

48. Barbagli G, Lazzeri M: Can reconstructive urethral surgery proceed without randomised controlled trials? Eur Urol. 2008; 54: 709-11.

49. Barbagli G, Lazzeri M: Reconstructive urethral surgery to be addressed at 2009 GURS meeting. AUANews. 2009; 14: 14.

50. Santucci RA, Mario LA, McAninch JW: Anastomotic urethroplasty for bulbar urethral stricture: analysis of $168 \mathrm{pa}-$ tients. J Urol. 2002; 167: 1715-9.

51. Barbagli G, De Angelis M, Romano G, Lazzeri M: Long-term followup of bulbar end-to-end anastomosis: a retrospective analysis of 153 patients in a single center experience. $J$ Urol. 2007; 178: 2470-3.

52. Guralnick ML, Webster GD: The augmented anastomotic urethroplasty: indications and outcome in 29 patients. J Urol. 2001; 165: 1496-501.

53. Morey AF, Kizer WS: Proximal bulbar urethroplasty via extended anastomotic approach--what are the limits? J Urol. 2006; 175: 2145-9.

54. Al-Qudah HS, Santucci RA: Buccal mucosal onlay urethroplasty versus anastomotic urethroplasty (AU) for short urethral strictures: which is better? J Urol. 2006; 175: 103.
55. Abouassaly R, Angermeier KW: Augmented anastomotic urethroplasty (AAR) in patients with dense urethral stricture disease. J Urol. 2006; 175: 38.

56. Barbagli G, Selli C, Tosto A, Palminteri E: Dorsal free graft urethroplasty. J Urol. 1996; 155: 23-6.

57. Barbagli G, Selli C, di Cello V, Mottola A: A one-stage dorsal free-graft urethroplasty for bulbar urethral strictures. $\mathrm{Br} J$ Urol. 1996; 78: 929-32.

58. Andrich DE, Leach CJ, Mundy AR: The Barbagli procedure gives the best results for patch urethroplasty of the bulbar urethra. BJU Int. 2001; 88: 385-9.

59. Wessells $\mathrm{H}$ : Ventral onlay graft techniques for urethroplasty. Urol Clin North Am. 2002; 29: 381-7.

60. Armenakas NA: Long-term outcome of ventral buccal mucosal grafts for anterior urethral strictures. AUA News. 2004; 9: 17-8.

61. Barbagli G, Palminteri E, Lazzeri M, Turini D: Interim outcomes of dorsal skin graft bulbar urethroplasty. J Urol. 2004; 172(4 Pt 1): 1365-7; discussion 1367.

62. Iselin CE, Webster GD: Dorsal onlay urethroplasty for urethral stricture repair. World J Urol. 1998; 16: 181-5.

63. Barbagli G, Palminteri E, Rizzo M: Dorsal onlay graft urethroplasty using penile skin or buccal mucosa in adult bulbourethral strictures. J Urol. 1998; 160: 1307-9.

64. Elliott SP, Metro MJ, McAninch JW: Long-term followup of the ventrally placed buccal mucosa onlay graft in bulbar urethral reconstruction. J Urol. 2003; 169: 1754-7.

65. Morey AF, McAninch JW: When and how to use buccal mucosal grafts in adult bulbar urethroplasty. Urology. 1996; 48: 194-8.

66. Barbagli G, Palminteri E, Guazzoni G, Montorsi F, Turini D, Lazzeri M: Bulbar urethroplasty using buccal mucosa grafts placed on the ventral, dorsal or lateral surface of the urethra: are results affected by the surgical technique? J Urol. 2005; 174: 955-7; discussion 957-8.

67. Abouassaly R, Angermeier KW: Cleveland clinic experience with buccal mucosa graft urethroplasty: intermediate-term results. J Urol. 2005; 173: 33.

68. Barbagli G, Sansalone S, Romano G, Lazzeri M: Ventral onlay oral mucosal graft bulbar urethroplasty. BJU Int. 2011; 108: $1218-31$.

69. Kulkarni S, Barbagli G, Sansalone S, Lazzeri M: One-sided anterior urethroplasty: a new dorsal onlay graft technique. BJU Int. 2009; 104: 1150-5.

70. Barbagli G, Mirri F, Gallucci M, Sansalone S, Romano G, Lazzeri M: Histological evidence of urethral involvement in male patients with genital lichen sclerosus: a preliminary report. J Urol. 2011; 185: 2171-6.

71. Barbagli G, Perovic S, Djinovic R, Sansalone S, Lazzeri M: Retrospective descriptive analysis of 1,176 patients with failed hypospadias repair. J Urol. 2010; 183: 207-11. 
72. Perovic S, Barbagli G, Djinovic R, Sansalone S, Vallasciani $S$, Lazzeri M: Surgical challenge in patients who underwent failed hypospadias repair: is it time to change? Urol Int. 2010; 85: 427-35.

73. Kulkarni SB, Barbagli G, Kirpekar D, Mirri F, Lazzeri M: Lichen sclerosus of the male genitalia and urethra: surgical options and results in a multicenter international experience with 215 patients. Eur Urol 2009; 55: 945-56.

74. Breyer BN, McAninch JW, Whitson JM, Eisenberg ML, Mehdizadeh JF, Myers JB et al.: Multivariate analysis of risk factors for long-term urethroplasty outcome. J Urol. 2010 183: 613-7.

75. Peterson AC, Palminteri E, Lazzeri M, Guanzoni G, Barbagli $G$, Webster GD: Heroic measures may not always be justified in extensive urethral stricture due to lichen sclerosus (balanitis xerotica obliterans). Urology. 2004; 64: 565-8.

\section{EDITORIAL COMMENT}

The manuscript entitled "Current Controversies in Reconstructive Surgery of the Anterior Urethra" is a review article on surgical treatment of anterior urethral strictures and hypospadias.

The authors have comprehensively reviewed this issue and organized the text according to six main controversial topics:

1. The use of oral mucosa vs penile skin in anterior urethra surgery

2. The use of free grafts vs pedicled flaps in penile urethroplasty

3. The use of grafts vs anastomotic repair in bulbar urethral strictures

4. The use of dorsal vs ventral placement of the graft in bulbar urethroplasty

5. The use of definitive perineal urethrostomy vs onestage repair in complex urethral stricture

6. The surgical options for patients with failed hypospadias repair

Reconstruction of the urethra is a challenging surgery for the urologists. Due to some circumstances that may occur at the time of surgery, the surgeon must be familiar with various surgical techniques.

In regards to the controversial topics raised by the authors, it is important to emphasize that well-design randomized trials are lacking in the literature. The few randomized studies compare non-homogeneous series of patients and stricture disease. So, it is an open-field for research.
76. Barbagli G, De Angelis M, Romano G, Lazzeri M: Clinical outcome and quality of life assessment in patients treated with perineal urethrostomy for anterior urethral stricture disease. J Urol. 2009; 182: 548-57.

77. Barbagli G, Perovic S, Djinovic R, Sansalone S, Lazzeri M: Retrospective descriptive analysis of 1,176 patients with failed hypospadias repair. J Urol. 2010; 183: 207-11.

78. Perovic S, Barbagli G, Djinovic R, Sansalone S, Vallasciani $\mathrm{S}$, Lazzeri M: Surgical challenge in patients who underwent failed hypospadias repair: is it time to change? Urol Int. 2010; 85: 427-35.

\section{Correspondence address}

Dr. Salvatore Sansalone Policlinico and University "Tor Vergata" Viale Oxford, 81 00133 Rome, Italy

E-mail: salvatore.sansalone@yahoo.it

Nevertheless, the review brings some interesting aspects to be pointed out:

- Oral mucosa and the penile skin are both excellent materials for substitution urethroplasty. A large series of patients presents better outcomes for oral mucosa. However, superiority of oral mucosa is to be proven with randomized studies.

- It is not possible to make evidence-based recommendations on the use of grafts versus pedicled flaps in penile urethroplasty. Nevertheless, in patients with lichen sclerosus the use of oral mucosa is mandatory (primary skin disease).

- $\quad$ Stricture length is the main factor to be analyzed before indicating graft versus end-to-end anastomosis in bulbar urethral strictures. Primary end-to-end anastomosis is suggested for 1-2 cm strictures.

- $\quad$ Case series suggest that different graft positions (ventral vs dorsal) have shown no difference in success rates for bulbar urethroplasty.

- It is important to listen to the patients' expectations before considering the use of a definitive perineal urethrostomy. It can be a less invasive option for complex urethral stricture.

- Patients with failed hypospadias repair should be treated in reference centers for urethral reconstructive surgery in order to greatly improve anatomical and functional outcomes.

Dr. Márcio Averbeck
Urologist
Porto Alegre, RS, Brazil Email: marcioaverbeck@gmail.com 